\title{
Linguagem e línguas - uma orientação básica filosófica.
}

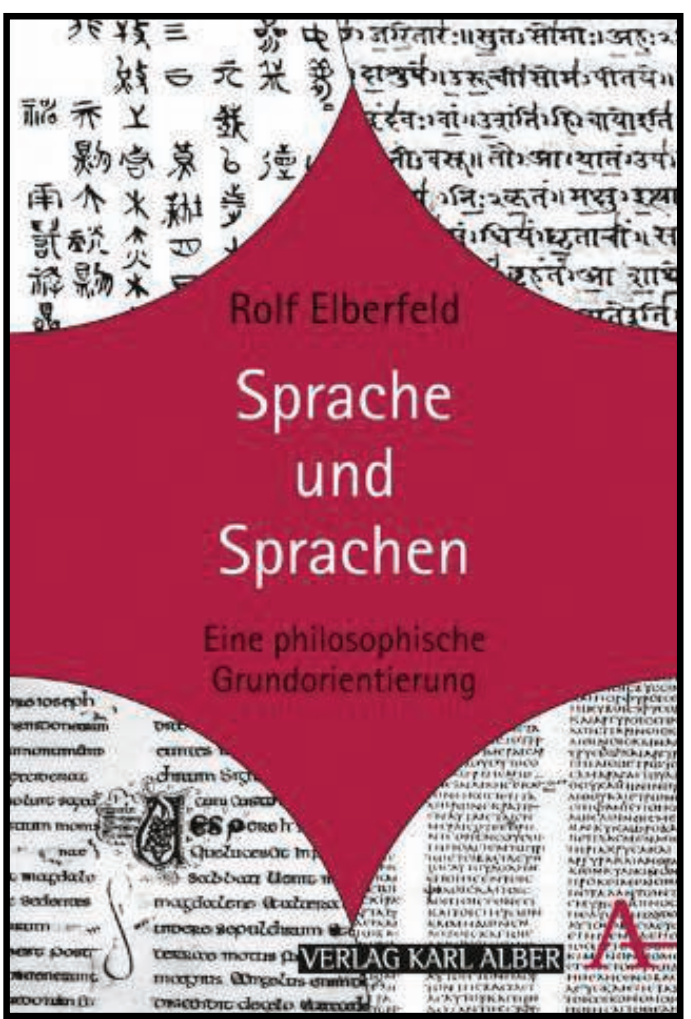

\section{por Lucas dos Reis Martins}

1rmartins@gmail.com

Doutorando CAPES-DAAD/Universität Hildesheim

ELBERFELD, Rolf. Sprache und Sprachen - Eine philosophische Grundorientierung. Freiburg: Karl Alber Verlag, 2012. 
Todos os dias somos levados a nos servir da linguagem em sua forma falada ou escrita, seja para se relacionar com os outros, conversando, expressando desejos, sentimentos, ou para refletir sobre o que acontece ao nosso redor ou com nós mesmos. Ao longo da vida nos expressarmos em nossa língua-mãe se torna tão natural e comum que raramente tomamos consciência da linguagem como um fenômeno constitutivo de nossas experiências. Situações nas quais nos faltam palavras ou que nos levam a mal entendimentos já trazem à tona pequenos questionamentos sobre a estrutura e os usos de nossa língua. Os questionamentos se multiplicam quando nos dispomos a aprender uma outra língua. Enquanto permanecemos nas línguas europeias, como inglês, alemão ou latim, encontramos com mais facilidade similaridades na estrutura e vocabulário com nossa língua portuguesa; quando nos dispomos a aprender línguas como chinês ou japonês, torna-se mais evidente e profunda a experiência do quão diversa pode ser uma língua estrangeira, seja em sua forma escrita ou falada.

Rolf Elberfeld, professor de Filosofia Cultural na Universidade de Hildesheim, Alemanha, nos apresenta o desafio e o potencial que a diversidade de línguas proporciona à filosofia, para muito além das fronteiras do pensamento europeu. Seu livro Linguagem e línguas não é um trabalho acabado, mas sim um guia que apresenta diversos caminhos que podem ser explorados pela filosofia ao redor do mundo à partir da diversidade de línguas. Elberfeld acredita que a diversidade de línguas ao redor de todo o mundo é um precioso tesouro a ser explorado pela filosofia: "A filosofia poderá, no início do século 21, ser menos restrita aos discursos da Europa e da América do Norte, de uma forma que nunca foi. Em consequência disso torna-se necessário levar a sério a diversidade de línguas como desafio para o desenvolvimento da filosofia no século XXI e refletir sobre o filosofar em um mundo global.

A filosofia é mais dependente do que nunca da diversidade de línguas - esta é a tese central das reflexões seguintes" [Pág. 17]. ${ }^{1}$

As diferentes possibilidades de tradução do próprio título do livro nos apresentam o eixo no qual o autor desenvolve suas reflexões. Sprache und Sprachen poderia ser traduzido tanto por Língua e línguas como por Linguagem e linguagens. Entretanto, sua intenção com a primeira palavra é se referir ao fenômeno Linguagem como um todo em seu sentido mais abrangente. Em função dessa intenção de uso, Elberfeld propõe que essa primeira palavra seja compreendida como um singulare tantum (designação gramatical para palavras que possuem apenas forma no singular, sem uma forma plural). Sprachen, que ortograficamente é simplesmente a primeira no plural, designaria um outro fenômeno: a variedade das

1ELBERFELD, Rolf. Sprache und Sprachen. p 17 
diferentes linguagens ou línguas no mundo. Portanto, se formássemos um singular a partir do segundo substantivo do título do livro, esse singular, apesar de ser ortograficamente idêntico ao primeiro, designaria algo diferente: uma linguagem específica, como a língua portuguesa ou a linguagem de sinais. Assim, optei por traduzir o título por Linguagem e Línguas. Apesar de iniciar o título com ênfase no fenômeno da linguagem em seu sentido mais abrangente, a autor cuida para não tomar nenhuma meta-perspectiva científica, consciente de que, antes de tudo, suas considerações tem como ponto de partida a própria língua alemã.

O primeiro capítulo dedica-se a uma breve apresentação da história da reflexão filosófica sobre a diversidade de línguas no pensamento europeu, começando por Platão e Aristóteles, passando por Francis Bacon e Gottfried W. Leibniz, encerrando com as reflexões de Friedrich Nietzsche e Martin Heidegger (entre outros). As reflexões sobre pensamento e linguagem feitas por Wilhelm von Humboldt desempenham um papel central no ponto de partida do autor, pois Elberfeld se esforça para não adotar um relativismo linguístico total (como adotam Edward Sapir ou Benjamin Lee Whorf) ou ainda um universalismo linguístico (como Noam Chomsky). O segundo capítulo se concentra em uma descrição do fenômeno línguas no mundo, com ênfase para as línguas naturais. Dessa forma, é feita uma breve descrição de línguas importantes para o desenvolvimento da filosofia ocidental como o grego antigo e o latim, sua relação com o as línguas modernas europeias e línguas que não tem relação com a família indo-europeia, no caso, o chinês e o japonês. $\mathrm{O}$ autor não desenvolve uma detalhada e exaustiva análise das línguas, mas busca trazer à luz pontos de diferença onde questões filosóficas podem ser levantadas de modo produtivo.

O quarto capítulo desenvolve sete exemplos concretos de reflexões linguístico-filosóficas no contexto intercultural (Ásia e Europa). O primeiro trata do sujeito na linguagem e no pensamento. Assim, são feitas considerações sobre a relação entre o desenvolvimento do sujeito gramatical e o desenvolvimento do que é sujeito na história da filosofia ocidental, o funcionamento de línguas orientais nas quais o sujeito não desempenha um papel central (e frases sem sujeito são mais frequentes e naturais) e similaridades com expressões usadas por Nietzsche e Heidegger (como a importância da partícula Es nos escritos desses filósofos). O segundo exemplo trata das vozes verbais em diferentes línguas, a voz ativa, passiva e a voz média. A voz média é uma forma verbal que foi esquecida formalmente pelas gramáticas ocidentais, mas que ainda possui um potencial de reconhecimento no campo semântico e no uso cotidiano das línguas modernas. A voz média abrange ações ou processos nas quais não há uma separação total do sujeito e do objeto. O grego antigo possui o reconhecimento gramatical dessa voz verbal, mas ainda assim de forma bastante inexata. Heidegger, em Ser e 
Tempo, refere-se à forma medial da palavra fenômeno em grego antigo para fundamentar a radicalidade de seu método fenomenológico. Elberfeld explora as possibilidades que uma recuperação do espaço semântico da antiga voz média abre para o pensamento contemporâneo ${ }^{2}$. O terceiro exemplo é a gramaticalização do tempo, tema relevante para a fenomenologia. O quarto exemplo explora o campo semântico de conceitos significativos para a filosofia. $\mathrm{O}$ autor se concentra em dois conceitos-chaves, um ocidental e um oriental: Cultura e 氣 (qi / $\mathrm{ki}$ - um conceito fundamental no pensamento oriental). O quinto exemplo trata do tema filosofia e tradução, com ênfase no processo cultural de transmissão e tradução do budismo da Índia para a China e da China para o Japão. O sexto exemplo tematiza a pragmática textual filosófica ${ }^{3}$. O último exemplo trata da filosofia e a arte de escrever, com ênfase na obra do filósofo japonês moderno Kitarō Nishida ${ }^{4}$. Todos os exemplos são sugestões concretas de caminhos a serem percorridos e nenhum deles é explorado exaustivamente no livro.

O quinto capítulo conclui o livro relacionando a diversidade de línguas com a fenomenologia transformativa. Na conclusão, o autor expressa claramente uma consequência prática de como suas sugestões podem ser desenvolvidas: "A fertilidade filosófica das perspectivas propostas pode ser provada e desenvolvida apenas através de numerosas análises fenomenológicas individuais. Portanto, espera-se em particular que todos que se dedicam à filosofia ao redor do mundo levem filosoficamente à sério suas respectivas línguas e libertem-se da fixação em apenas uma língua como a única língua válida para a filosofia, seja qual for a língua. Pois cada língua possui potencialidades filosóficas, que se obtém apenas no descobrir. Filosofar será no futuro mais dependente do que nunca da diversidade de línguas"s. De que modo essa sugestão de Elberfeld pode ser útil para aqueles que se dedicam e produzem filosofia no Brasil e a partir dele em português?

Recentemente, na Feira do Livro de Frankfurt de 2013, o escritor brasileiro Luiz Ruffato proferiu o discurso de abertura: "O que significa ser escritor num

2 Sobre a voz média, Elberfeld proferiu uma comunicação em 2008 no Brasil, no III Colóquio sobre o Pensamento Japonês coordenado por Antonio Florentino Neto e Zeljko Loparic. Com o título: Vacuidade e Voz Média, formas do uso da linguagem em Nishida e Nishitani que foi traduzida e publicada em: LOPARIC, Zeljko. A Escola de Kyoto e o Perigo da Técnica, Dwwe, São Paulo, 2009

3 Nesse tópico, o autor possui publicada sua habilitação Fenomenologia do tempo no Budismo, que explora um método intercultural de pragmática textual com um texto do monge budista Dōgen. ELBERFELD, Rolf: Phänomenologie der Zeit im Buddhismus. Methoden interkulturellen Philosophierens, Frommann-Holzboog, Stuttgart-Bad Cannstatt, 2004.

4 A tese de doutorado do autor dedica-se também ao tema: ELBERFELD, Rolf. Kitarō Nishida (1870-1945). Das Verstehen der Kulturen. Moderne japanische Philosophie und die Frage nach der Interkulturalität, Rodopi, Amsterdam, 1999.

5ELBERFELD, Rolf. Sprache und Sprachen. p 384 
país situado na periferia do mundo, um lugar onde o termo capitalismo selvagem definitivamente não é uma metáfora? Para mim, escrever é compromisso. Não há como renunciar ao fato de habitar os limiares do século 21, de escrever em português, de viver em um território chamado Brasil. (...) o que significa habitar essa região situada na periferia do mundo, escrever em português para leitores quase inexistentes, lutar, enfim, todos os dias, para construir, em meio a adversidades, um sentido para a vida? Eu acredito, talvez até ingenuamente, no papel transformador da literatura". Eu penso que o termo ser escritor pode ser compreendido em todo o discurso de Ruffato também como filosofar. E vi semelhanças, confesso que um pouco forçadas, entre o papel transformador da literatura citada por Ruffato e a proposta de uma fenomenologia transformativa por Elberfeld. Para Elberfeld, Kitarō Nishida é o primeiro filósofo que produz de fato uma filosofia intercultural, isto é, desenvolve um pensar que tem seus fundamentos entre a cultura europeia e a japonesa. A forma de escrever de Nishida questiona uma separação convencional entre filosofia e arte. Ler filosoficamente a descrição de um escritor sobre nosso país pode nos impulsar a entender o que pode significar fazer filosofia no século XXI, na periferia do mundo, em português. O que significa o fenômeno da diversidade das línguas para um país continental na América do Sul que ainda possui uma infinidade de línguas indígenas muito distantes do indo-europeu (nos séculos XVI e XVII falava-se predominante Tupi no Brasil), mas que ainda hoje tem toda essa diversidade linguística e cultural em risco de extinção. Ao se falar do significado filosófico no Brasil da diversidade de línguas é impossível não abordarmos o significado do genocídio indígena que não está de forma alguma totalmente no passado. Com o retorno da filosofia como disciplina obrigatória no ensino básico de todo o país e a implementação de uma lei de cotas mais eficiente para as universidades públicas, eu acredito que todas essas questões ganham importantes potencialidades de mudança para a sociedade. O ex-diretor da Escola da Ponte, José Pacheco, ao tentar sugerir uma forma de como tratar do problema educacional no Brasil, e remetendo-se ao pedagogo Paulo Freire, se deparou com a ausência de um termo no português e criou um neologismo: suliar. Quer dizer, virar-se mais para o nosso sul e não nortear, ou seja, pensar modelos europeus e estadunidenses como soluções para nossos problemas. O que poderia significar suliar para a filosofia no Brasil? Uma inversão radical de nossos mapas filosóficos talvez seja uma tarefa interessante que se apresenta àqueles que se dedicam à filosofia no Brasil e a partir dele, dispondo-se a pensar e desenvolver as questões interculturais com as quais o fenômeno da diversidade de língua, em um mundo global no início do século XXI, nos desafia.

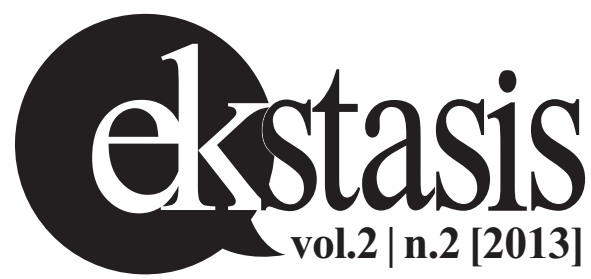

